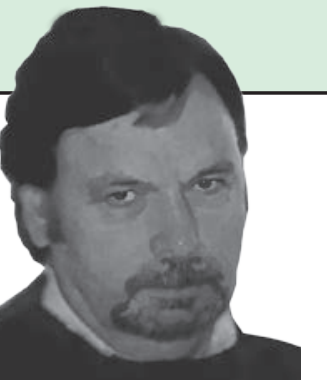

С. Ю. КУЗНЕЦОВ

Кандидат экон. наук, доцент кафедры «Экономика

и антикризисное управление» ФГОБУ ВПО «Финансовый университет при Правительстве

Российской Федерации».

Имеет тридцатилетний опыт педагогической деятельности. Окончил докторантуру Финансового университета. Является автором монографии по стратегическому управлению маркетинговыми активами и учебного пособия по антикризисному управлению. Имеет публикации как в России, так и за рубежом. Основные направления исследований: стратегический антикризисный менеджсмент, стратегический маркетинг, оценка и управление маркетинговыми активами компании, оценка и управление стоимостью бизнеса.

E-mail:ksu_54@mail.ru
$\mathrm{Y}$

стойчивость бизнеса является концепцией ресурсной теории фирмы. Теория ресурсов исследует структуру ее активов, ее ключевые способности, устойчивые конкурентные преимущества, дифференциацию и рентабельность. На основе дифференциации происходит стоимостное управление как комплексное наращенное потребительское решение, как эффективное управление постиндустриальной ценностью устойчивой фирмы. Новая экономика устойчивого предприятия - экономика потребительского «притяжения» постепенно дополняет и вытесняет индустриальную микроэкономику продуктового «выталкивания». Потребитель центр организации устойчивого бизнеса, а управление отношениями с потребителем - важный элемент эффективной антикризисной бизнес-стратегии.

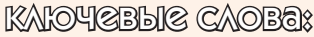

главные стейкхолдеры, клиентоориентированная компания, лояльность потребителей, микроэкономика устойчивого «притяжения», потребители, ресурсная теория фирмы, устойчивые конкурентные преимущества.

\title{
Cовременная yправленческая
}
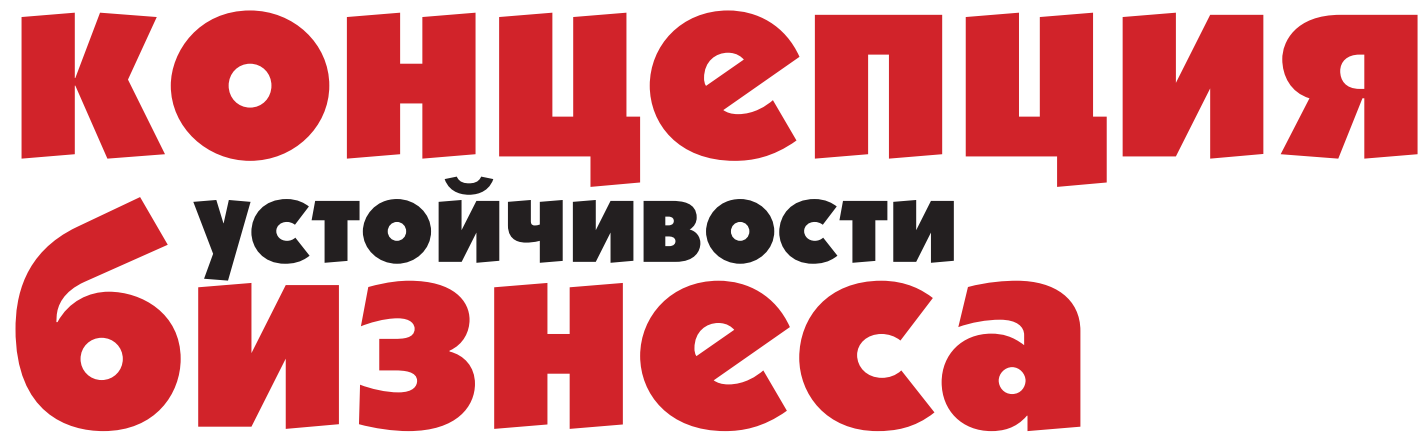

\section{Ресурсная теория фирмы}

Теоретически проблема устойчивости бизнеса базируется на ресурсной теории фирмы. Успешные фирмы создают большую ценность в результате комбинации ресурсов, чем они ex ante стоят по отдельности. Сущность ресурсной теории фирмы заключается в том, что ключевые ресурсы фирмы используются менеджментом и конвертируются в устойчивые конкурентные преимущества, выражающиеся в блестящих результатах деятельности фирмы.
Ресурсная теория фирмы тесно связана с системным подходом к управлению ею, который реализуется путем определения субъектов, объектов, ключевых элементов управления. Устанавливаются стратегические цели предприятия, бизнес-стратегия как модель, направление долгосрочных действий для достижения поставленных целей. Создается организационная структура. В ее рамках осуществляются инвестиции, инвестиционные проекты, создаются ресурсы и активы, текущие бюджеты и бизнес-процессы и т. д. 
В ресурсной теории фирмы используются следующие краеугольные понятия, которые взаимосвязаны между собой:

- ресурсы, активы, имущество, отношения;

• ключевые способности и компетенции;

- дифференциация;

• устойчивые конкурентные преимущества.

Теоретические и практические разграничения между ними пока недостаточно четко оформлены в разных работах. В рамках ресурсной теории ресурсы фирмы служат основой для понимания способностей, устойчивых конкурентных преимуществ, дифференциации и рентабельности. Нам представляется, что краеугольные понятия описывают ресурсы, которые реализуются на разных уровнях анализа (табл. 1).

Отношения с каждой группой участников важны для стратегического управления здоровьем предприятия. В постиндустриальной экономике ключевую роль в управлении всеми отношениями играют отношения с потребителями. Именно потребители, совершающие покупки, создают денежные притоки предприятия, которые составляют материальную и финансовую основу благополучия других участников. Не случайно в антикризисной теории и практике предприятий ухудшение их положения (первая стадия, или кризис рыночной стратегии фирмы) начинается с падения продаж и потери потребителей, разочаровавшихся в предлагаемых ценностях. Разрушение деловой репутации фирмы начинается с эрозии потребительских ценностей и лояльности. Таким образом, через управление рынком на основе рыночных ценностей все общественные участники фирмы (собственники, инвесторы, менеджмент, сотрудники, потребители, кредиторы, государство, поставщики, клиенты, общественность) приобретают заинтересованность в фактической успешности ее деятельности (табл. 2).

В связи с переходом к постиндустриализму современная экономическая и управленческая литература пока нечетко разграничивает понятия ресурсной теории фирмы. Активы - ресурсы, которые предприятие контролирует в результате прошлых событий и с которыми связывает ожидания экономических выгод в будущем. Ресурсы факторы генерации стоимости для компании, контролируемые менеджментом. Активы организации - ресурсы, постепенно накапливаемые через инвестиции. Теория стоимости на базе ресурсов постулирует, что неимитируемые, незаменяемые, редкие и ценные ресурсы позволяют создать устойчивые конкурентные преимущества и способности, которые обеспечивают высокие результаты функционирования фирмы. Ресурсы и способности состоят из материальных и нематериальных активов. Устойчивые конкурентные

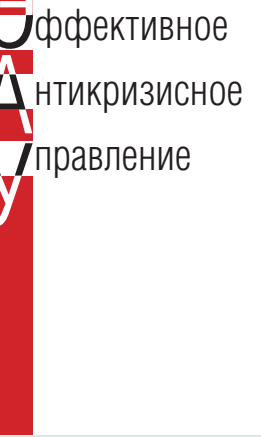

Таблица 1

Экономическое содержание ресурсов

\begin{tabular}{|l|}
\hline \multicolumn{1}{|c|}{ Экономическое содержание } \\
\hline Материальные и нематериальные активы \\
\hline Знания, навыки, умения \\
\hline Отношения с потребителями и другими участниками \\
\hline Рентабельность, стоимость бизнеса \\
\hline
\end{tabular}

преимущества - это во многом отношенческие активы фирмы. Устойчивые конкурентные преимущества получают маркетинговую оценку предложение большей ценности, чем у конкурентов, и финансово-рыночную оценку - рост капитализации фирмы.

Еще в 1930-е годы в работах Chamberlin (1933) и Robinson (1933) и далее, в 1950-е годы, в работах о росте фирмы Е. Penrose (1959) несовершенная, монополистическая конкуренция, дифференциация и получение фирмой рентабельности сверх нормальной, средней по отрасли объяснялись стратегическим управлением ключевыми ресурсами, которые обладают высокой ценностью, сложны для имитации. Chamberlin идентифицировал ключевые способности фир-

Сопоставление элементов ресурсной теории и участников фирмы

Сопоставление элементов ресурсной теории и участников фирмы
\begin{tabular}{|l|l|}
\hline \multicolumn{1}{|c|}{ Элемент теории } & \multicolumn{1}{|c|}{ Категория участников фирмы } \\
\hline $\begin{array}{l}\text { Стратегический выбор ресурсов и их организация } \\
\text { (ценность стратегического знания в условиях рыночной } \\
\text { неопределенности) }\end{array}$ & Собственники, акционеры и менеджмент \\
\hline Ресурсы, активы, способности и компетенции & Потребители, кадры, менеджмент \\
\hline Устойчивые конкурентные преимущества, дифференциация & Потребители и прочие участники \\
\hline Деятельность, функции организации & Менеджмент, персонал \\
\hline $\begin{array}{l}\text { Финансово-экономические измерители ценности: доходы, } \\
\text { ренты, стоимость капитала }\end{array}$ & Собственники, акционеры, менеджмент \\
\hline
\end{tabular}

мы: технические знания, репутацию, известность потребителям ее торговых марок и бренда, патенты и организацию управления. В более поздних работах в литературе по стратегическому управлению и маркетингу (Porter, 1980; Nelson, 1991) идеи о значимости стратегии, организации и ключевых способностях получили новое развитие. М. Портер показал, как фирмы могут позициони- 
ровать себя и успешно функционировать при наличии пяти сил внутри отрасли. В работах Oliver (1997) и Rao (1994) отражено дальнейшее развитие портеровской модели конкуренции с учетом современных ограничений рационального поведения фирмы, с учетом социальных обменов ценностями в рамках институционального направления мысли. В исследованиях Kotler (1994) раскрывается центральная идея концепции устойчивых конкурентных преимуществ: предоставление потребителям большей ценности в рамках пула ресурсов приводит к благоприятной рыночной деятельности фирмы, оцениваемой как рост доли рынка и уровня удовлетворенности потребителей; а также финансовой деятельности, которая выражена как рост рентабельности, стоимости бизнеса.

Определим устойчивые конкурентные преимущества так: длительные выгоды от применения стратегии созидания стоимости, которая не может одновременно быть продублирована и использована любым потенциальным или существующим конкурентом.

Отдельный важный вопрос - о месте дифференциации в ресурсной теории и капитализации ее преимуществ. Прогрессирующая дифференциация в разных сферах накапливает отличительные преимущества инновационной фирмы во всем масштабе ее воспроизводства. Дифференциация продуктов создает основополагающее конкурентное преимущество в управлении изменениями. Она формируется в аллокации стоимостных вкладов, бюджета и инвестиций путем идентификации активов. Можно анализировать совокупный процесс создания капитальной стоимости через дифференциацию фирмы по следующим объектам:

- продукты (качество);

- структура организации (управление изменениями, реструктуризация);

- комплексные потребительские решения (управление потребителями); процессы (реинжиниринг бизнес-процессов);

- кадры (наем, увольнения);

- финансы,

• портфель маркетинг-микса и пр.

На основе дифференциации осуществляется управление ценностью и стоимостью устойчивого бизнеса как комплексное наращенное потребительское решение, как управление постиндустриальной ценностью фирмы. В результате конкурентные преимущества фирмы можно было бы также считать и учитывать как важный актив. Если преимущества нельзя выделить, то они формируют гудвилл фирмы. Если их можно идентифицировать как маркетинговые преимущества, то благодаря росту выручки и прибыли, экономии на стоимости складских материалов и технологии сбора дебиторской задолженности их можно капитализировать.

Таким образом, с устойчивостью конкурентного бизнеса растет стоимость интеллектуальных преимуществ в производстве (технологии и ноухау), обмене (маркетинговые активы и инвестиции, финансовый инжиниринг), потреблении (решения для лояльных потребителей).

Проблема устойчивости бизнеса является не только российской, но и мировой проблемой. Последние международные опросы показывают, что для большинства (93\%) руководителей крупнейших компаний устойчивость является важным пунктом для будущего успешного развития бизнеса. С 2007 года ответственность капитанов мирового бизнеса в отношении устойчивости бизнеса фундаментально выросла. За последние почти 100 лет растущая глобальная конкуренция, технологические сдвиги и наиболее серьезный экономический и финансовый кризис только усилили эту ответственность, связав ее с сутью самого бизнеса и его ценностями.

В современной мировой управленческой литературе существуют трактовки устойчивости в широком и узком смысле. Широкие рамки охватывают не только экономический, но и социальный контекст, а также проблемы защиты окружающей среды. Определенная таким образом в документах $\mathrm{OOH}$ устойчивость возникает при эффективном управлении ресурсами без нанесения ущерба обществу и окружающей среде.

Трактовки понятия в узком смысле включают долгосрочное благополучие организации на фоне еe высокорезультативного функционирования. С позиции управления устойчивость бизнеса связующее качество современного стратегического антикризисного менеджмента, стремящегося перейти от угроз и использования слабых сторон к возможностям, сильным сторонам и длительному успеху.

Устойчивость катализирует экономический рост на базе инноваций и бизнес-культуры для обеспечения потребностей партнеров и потребителей фирмы. Устойчивость формируется как на стратегическом, так и на тактическом управленческом уровне организации, включая бизнес-процессы и операции. На стратегическом уровне она проявляется в дифференциации в долговременных стратегических целях, устойчивой деловой репутации, стоимости бренда, инновационных продуктах, услугах и работах, протестированном маркетингом имуществе, долгосрочном стратегическом партнерстве и в управлении отношениями с потребителями (CRM). На тактическом уровне превосходства устойчивость 
формируется на базе сокращения операционных издержек и обеспечения бережливости бизнеспроцессов на ключевых производствах, развитии новых бизнес-моделей и источников инноваций, изменяет отраслевые структуры затрат.

В данной статье устойчивость бизнеса рассматривается в пределах широкого определения, но, как правило, без учета экологических проблем. Мы исходим из современного воззрения на предприятие как совокупность трех ключевых объектов управления:

- имущественного комплекса активов;

- социально-экономических отношений участников с данным предприятием;

- организационного набора технологий, инноваций и бизнес-культуры.

Традиционно предприятие рассматривается как имущественный комплекс различных активов: материальных, финансовых, нематериальных. В постиндустриальной экономике большое значение для его функционирования имеют трудовые ресурсы, клиентская база, организационная структура.

Современное предприятие также исследуется как совокупность социально-экономических отношений его участников (дольщиков, стейкхолдеров (stakeholders). Если предприятие как имущественный комплекс оценивается преимущественно по финансовым показателям стоимости его активов (чистых активов), то его важность как совокупности отношений определяется не только и не столько финансовыми (количественными), но и нефинансовыми (качественными, «мягкими») показателями ценности этих отношений. Так, взаимоотношения труда и менеджмента, предприятия-должника и кредиторов, менеджеров и инвесторов, предприятия и потребителей его продукции описываются скорее качественными понятиями, включая партнерство, доверие, удовлетворенность, лояльность, кризис, конфликт, предательство и т. п.

Так, управление активами и продуктами сочетается с управлением отношениями с потребителями. Эффективное управление активами невозможно без управления отношениями ценности между участниками компании. Согласно последнему международному опросу руководителей компаний, потребители - главные участники $(58 \%)$, далее идут сотрудники ( $45 \%)$ и правительство (39\%). Эти два подхода (имущественный и отношенческий) применимы к изучению устойчивости современного предприятия.

В современных условиях постиндустриализма особого внимания заслуживает организационный набор технологий, инноваций и бизнес-культуры. Впрочем, в рамках данной статьи достаточно рас- смотреть первые два ключевых объекта управления. Ведь между нематериальными активами (технологиями и инновациями) и отношенческим капиталом (организация, отношения и культура) можно распределить третий объект управления.

Устойчивость бизнеса тесно связана с ключевыми объектами управления предприятия через основные факторы долгосрочного экономического успеха предприятия, к которым относятся:

- здоровая конструктивная стратегия как формализованное знание целей и путей их достижения;

- производительные активы отличного качества, в том числе нематериальные;

• инновационные товары, услуги, работы, процессы;

- прочная деловая репутация фирмы с точки зрения всех ее участников, включая PR; долгосрочные партнерские отношения, лояльность, доверие - вот характеристики предложения ценности такой фирмы;

- способность привлекать, удерживать и развивать управленческие и трудовые таланты, а также потребителей.

Также следует соблюдать баланс долгосрочных и краткосрочных целей, осуществляя выравнивание функциональной и текущей эффективности. На базе операционного здоровья созидательные разрушения будут поддерживать долгосрочную устойчивую конкурентоспособность.

Важной характеристикой постиндустриализма становится новая экономика устойчивых предприятий - экономика потребительского «притяжения» (pull economy) в дополнение к индустриальной экономике продуктового «выталкивания» (push economy). Экономика притяжения меняет место потребителей в воспроизводственной и стоимостной цепочке предприятия. Компания становится клиентоориентированной и клиентоцентричной. Потребитель оказывается ключевым звеном организации бизнеса, а управление отношениями с потребителем считается наиболее важной характеристикой бизнес-стратегии.

В последнее столетие индустриальные предприятия занимались главным образом поисками эффективного управления производством и реализацией на основе «выталкивания» массовой продукции в сферы рынка, где ожидался потребительский спрос. В идеале жесткие и стандартизированные бизнес-процессы направляют ограниченные ресурсы предприятия в планируемые сферы в определенное время. Эта жесткость вынуждает предприятия направлять усилия на обеспечение роста эффективности, контролируемого
Z̈рфективное

нтикризисное

правление 
внутри фирмы. Однако по мере усложнения спроса и увеличения трудоемкости его анализа потребители все более становятся для предприятий пассивными покупателями «выталкиваемой» на рынок продукции. Стандартизированный процесс инноваций вступает в противоречие с непре-

Теоретические рамки микроэкономики маркетинговой устойчивости

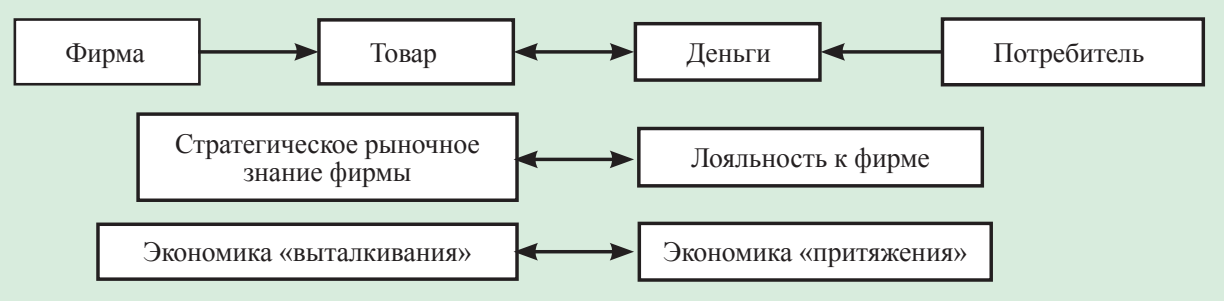

Вместо размещения в конце стоимостной цепочки (product push) потребитель находится во многом в ее начале (consumer pull) (см. рисунок). Первостепенная задача постиндустриальных клиентоориентированных компаний - управление отношениями с активными потребителями.

Перечислим черты экономики устойчивого «притяжения»:

- компании становятся клиентоцентричными: клиенты - это потребители для розничной сферы В2С и партнеры для оптовой сферы В2В, центр постиндустриальной микроэкономики смещается к потребителям и партнерам предприятий;

- лояльность потребителей, бренды и партнерские отношения становятся маркетинговыми нематериальными активами предприятия;

- лояльные потребители - не пассивные, а активные участники предприятия при реализации ценности компании;

- потребители проактивно «притягивают» к себе продукцию, а не реагируют на «выталкивание» предприятием своей продукции на рынок: суть микроэкономики устойчивого предприятия не в выталкивании товаров, а в инновационном умножении потребительского опыта и удовлетворенности от опыта взаимоотношений с фирмой;

- Интернет создает устойчивым фирмам дигитальные активы, а проактивным потребителям новые индивидуальные средства коммуницирования для получения разнообразной рыночной информации, например через блоги, форумы, социальные сети.

В самом общем виде структуру активов предприятий традиционной экономики «выталкивания» можно представить следующим образом. Материальные активы преобладают. Человеческий капитал привязан к производственным целям. Капитал брендов определяется «выталкивающими» продажами. Структура активов предприятий экономики «притяжения» другая: преобладает капитал брендов от потребительского «притяжения». Человеческий капитал клиентоориентирован. Внеоборотные активы не так значительны. Электронный бизнес также позволяет предприятиям материальной сферы приближаться к такой нематериальной основе, используя аутсорсинг отраслевых производственных и вспомогательных (финансовых, учетных) процессов.

Сегодня экономика «притяжения» организуется как сетевая экономика во многом на пограничной периферии предприятий. Растет число сетевых предприятий, которые используют Интернет и социальные сети (блоги, видеосервис) для увеличения интеракций между сотрудниками но инициировать бизнес-транзакции, а не просто реагировать на деятельность отделов продаж фирм. 
внутри предприятий для достижения стратегических целей последних.

Формируются глобальные процессные сети как новая сетевая система мобилизации ресурсов многих предприятий - долгосрочных партнеров в операционных процессах управления снабжением, производством и отношениями с клиентами (табл. 3).

Преимуществами новой экономики устойчивых предприятий «притяжения» являются:

- рост контрольной доли рынка, выручки рентного преимущества в экономике «выталкивания»;

• оптимизация и рост денежных потоков в новой экономике.

\section{ВЫводы}

Устойчивость бизнеса является производной концепцией ресурсной теории фирмы, которая исследует структуру ее активов, ключевые способности, устойчивые конкурентные преимущества, дифференциацию и рентабельность. 亏ффрективное

$\Delta$ нтикризисное

правление

Таблица 3

Основные черты микроэкономики «выталкивания" и экономики «притяэения» [2, с. 22]

\begin{tabular}{|c|c|c|}
\hline Сфера & Экономика «выталкивания» & Экономика «притяжения» \\
\hline Внешняя среда и спрос & $\begin{array}{l}\text { Возможность прогнозировать состояние внешней } \\
\text { среды и спрос, их рассмотрение скорее как угроз }\end{array}$ & $\begin{array}{l}\text { Оценка внешней среды и спроса как неопределенных, имеющих } \\
\text { возможные преимущества }\end{array}$ \\
\hline Инновации и производство & $\begin{array}{l}\text { Дизайн и проектировки по принципу «сверху } \\
\text { вниз», жестко ограниченные и стандартизирован- } \\
\text { ные программы реинжиниринга и спецификаций }\end{array}$ & $\begin{array}{l}\text { Непрерывное, по мере возникновения, внедрение инноваций, ко- } \\
\text { торые выполняются гибко и быстро; открытые к сотрудничеству } \\
\text { платформы модулей }\end{array}$ \\
\hline Ведущие кадры & $\begin{array}{l}\text { Инженеры, финансовые менеджеры, бренд- } \\
\text { менеджеры }\end{array}$ & $\begin{array}{l}\text { Инженеры, финансовые менеджеры, бренд-менеджеры, которые } \\
\text { являются штатными сотрудниками данного предприятия, и те, } \\
\text { кто работают в других фирмах }\end{array}$ \\
\hline Финансы & Традиционный финансовый менеджмент & $\begin{array}{l}\text { Традиционный финансовый менеджмент, управление денежными } \\
\text { потоками от увеличения рычага ресурсов третьих лиц }\end{array}$ \\
\hline Управление & $\begin{array}{l}\text { Централизация и контроль решений, управление } \\
\text { инструкциями }\end{array}$ & Децентрализация и инициативы, управление лидерством \\
\hline Организация & $\begin{array}{l}\text { Вертикальная, иерархичная, матричная, ресур- } \\
\text { соцентричная организация, слабо связанные } \\
\text { организационные силосы, очерченные процедуры }\end{array}$ & $\begin{array}{l}\text { Горизонтальная, плоская, сетевая, клиентоцентричная орга- } \\
\text { низация; расширение набора модулей, инструментов и круга } \\
\text { партнеров }\end{array}$ \\
\hline Число клиентов & Очень ограниченное число клиентов & $\begin{array}{l}\text { Неограниченное число клиентов за счет открытости для разных } \\
\text { участников }\end{array}$ \\
\hline Цель & Операционная эффективность & Инновации \\
\hline
\end{tabular}

и операционной маржи относительно несетевых конкурентов;

- интенсификация инноваций посредством увеличения рычага ресурсов третьих лиц;

- снижение затрат на поддержание взаимоотношений, рост ценности для всех участников;

- больший масштаб благодаря сотрудничеству;

- проактивность клиентов в отношениях с предприятиями;

- гибкость финансирования и распределения ресурсов;

• противодействие снижению факторов конку-
На основе дифференциации осуществляется стоимостное управление как комплексное наращенное потребительское решение и управление постиндустриальной ценностью устойчивой фирмы. Новая экономика устойчивого предприятия экономика потребительского «притяжения» - постепенно дополняет и вытесняет индустриальную микроэкономику продуктового «выталкивания». Потребитель выходит в центр организации устойчивого бизнеса, а управление отношениями с потребителем становится важным элементом эффективной антикризисной бизнес-стратегии.

\section{GUपhCOR}

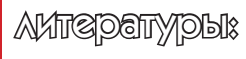

1. Кузнецов С. Ю. Антикризисное управление. Курс лекций: Учеб.-метод. пос. М.: Финансы и статистика, 2010.176 с.

2. Кузнецов С. Ю. Стратегическое управление маркетинговыми нематериальными активами предприятия.

М.: Финакадемия, 2008. 144 с.

3. A New Era of Sustainability. UN Global Compact-Accenture CEO Study 2010 // Accenture: Электронный ресурс. Режим доступа: http://www.accenture.com/SiteCollectionDocuments/PDF/Accenture_A_New_Era_of_Sustainability_CEO_Study.pdf. 